\title{
De perto e de longe: a política de uma autoantropologia
} Kaiowá

\author{
From near and far away: the politics of a Kaiowá \\ self-anthropology
}

\author{
Bruno Martins Morais ${ }^{1}$
}

DOI: http://dx.doi.org/10.20435/tellus.v20i41.646

\begin{abstract}
Resumo: Variando o tom entre ensaio e resenha crítica, este artigo analisará o trabalho de Izaque João, um acadêmico indígena Kaiowá que defendeu seu mestrado em História, na Universidade Federal da Grande Dourados, com a dissertação "Jakaira Reko Nheypyrũ Maragatu Mborahéi: origem e fundamentos do canto ritual Jerosy Puku entre os Kaiowá de Panambi, Panambizinho e Sucuri'y, Mato Grosso do Sul". Estaremos atentos à metodologia empregada e aos modos de enunciação para explorar as variações discursivas da posição do autor em campo - às vezes perto, às vezes longe de sua comunidade -, em uma tentativa de delinear os limites de uma autoantropologia e o potencial político que ela carrega.
\end{abstract}

Palavras-chave: autoantropologia; política; Kaiowá.

Abstract: Varying the tone between essay and review, this article will analyze the work of Izaque João, an indigenous Kaiowá scholar who defended his master's degree in History at the Federal University of Grande Dourados with the dissertation "Jakaira Reko Nheypyrũ Maragatu Mborahéi: Origin and Foundations of ritual singing Jerosy Puku among the Panambi, Panambizinho and Sucuri'y Kaiowá, Mato Grosso do Sul". We analyze the methodology employed and the modes of enunciation to explore the discursive variations of the author's position in the field - sometimes close, sometimes far away from his community -, in an attempt to delineate the limits and the political potential of self-anthropology.

Keywords: auto-anthropology; politics; Kaiowá.

\footnotetext{
${ }^{1}$ Pontifícia Universidade Católica do Paraná (PUCPR), Curitiba, Paraná, Brasil.
} 


\section{INTRODUÇÃO}

"Se você está achando que vai fazer sua antropologia sentado aí na aldeia, tomando tereré, você está muito enganado!", me espremeu um Kaiowá na minha primeira entrada em campo, "o branco não pode vir aqui e levar mais nossa palavra, de graça".

Em meio a um turbilhão de conflitos fundiários, que a todo tempo exigem relatórios de identificação, perícias e despertam o interesse da Academia, os Kaiowá do Sul de Mato Grosso do Sul desenvolveram um agudo senso crítico à pesquisa antropológica. O que parece que meu interlocutor estava sugerindo é que já não há espaço para o "saque antropológico", para a pesquisa descompromissada. O campo é uma troca, e em toda troca há política - que política posso oferecer eu, como antropólogo?

Desde o célebre artigo de Roberto Cardoso de Oliveira (1996) que advogava um "indigenismo (auto)crítico", já se acumulou na Academia brasileira alguma discussão quanto aos compromissos da antropologia para com os povos que ela estuda. Ainda assim, parece que para essa pergunta ainda não foi encontrada uma resposta. A Declaração de Barbados (1971)² já apontava, ao indigenismo, o caminho de "aproveitar todas as conjunturas que se apresentem dentro do atual sistema para atuar em favor das comunidades indígenas" e

[...] denunciar por todos os meios os casos de genocídio e as práticas etnocidas, assim como voltar-se para a realidade local para teorizar a partir dela, a fim de superar a condição subalterna de simples exemplificadores de teorias. (DECLARAÇÃO DE BARBADOS, 1971)

A Associação Brasileira de Antropologia leva o debate da militância antropológica ao rumo da regulamentação do exercício da profissão, discutindo a relevância política dos laudos periciais e relatórios técnicos (LEITE, 2005). Mauro Almeida (2013), mais recentemente, pronunciou-se em defesa de uma antropologia fair play, uma ética de pesquisa guiada por um consentimento prévio e informado, que

\footnotetext{
${ }^{2}$ A Declaração de Barbados de 1971, subscrita por quatro antropólogos brasileiros - entre eles, Darcy Ribeiro - que assistiam ao Simpósio sobre a Friç̧ão Interétnica na América do Sul, foi declaradamente a fonte de inspiração para o ressurgimento da Associação Brasileira de Antropologia (ABA), em 1974, e para a Associação Nacional de Apoio ao Índio (ANAI), em alguns lugares chamadas de Comissões Pró-Índio (CPI), a partir de 1976.
} 
delimite o uso e a reprodução das informações colhidas em campo. Nisso estaria implicado esclarecer aos interlocutores os limites da pesquisa científica - o que também não responde à pergunta, apenas esclarece os seus termos.

Saindo pela tangente, tem-se apontado que a formalização da educação indígena e o crescente acesso dos nativos à universidade impõem uma nova volta no problema do engajamento do investigador. Para tentar vislumbrar uma saída, reformulemos a questão: se o pesquisador fosse nativo, a mesma interrogação se imporia? A pesquisa nativa tem por vocação um compromisso com os projetos de seu povo?

Este artigo, entre um tom de ensaio e resenha crítica, dirige essas perguntas ao trabalho de um acadêmico Kaiowá produzido no bojo do Programa de PósGraduação em História da Universidade Federal da Grande Dourados. Sob o título de "Jakaira Reko Nheypyrũ Maragatu Mborahéi: origem e fundamentos do canto ritual Jerosy Puku entre os Kaiowá de Panambi, Panambizinho e Sucuri'y, Mato Grosso do Sul", Izaque João defendeu, em 2011, seu título de mestre. O cerne da dissertação é uma análise do canto ritual que opera por sobre o milho saboró, Jerosy Puku, batizando-o e permitindo o consumo humano. A dissertação, no entanto, etnografa elementos da escatologia e da concepção Kaiowá do tempo, mesclando-as com um método de história oral; a análise do rito vai se desdobrar a partir de uma memória coletiva Kaiowá, e a narrativa que daí emerge dá especial atenção ao papel desempenhado pelos rezadores que performam o canto.

Apesar de não ter sido defendido em um programa de pós-graduação em antropologia, o trabalho é de uma impressionante carga etnológica e permite vislumbrar os impasses de um pesquisador nativo em campo entre os seus pares. Estarei atento à metodologia empregada e aos modos de enunciação, tentando traçar os contornos do que seria uma autoantropologia no caso de Izaque. Os referenciais teóricos de Karin Narayan (1993), ela mesma antropóloga "meio nativa", e Marilyn Strathern (1987) ajudarão a burilar a aparente contradição com que o autor se posiciona, de perto e de longe, em relação aos sujeitos de seu estudo e à comunidade que ele mesmo faz parte.

Mas, se há algum engajamento político nesse trabalho de um Kaiowá, ele estará na maneira com que o discurso nativo se equipara ao discurso acadêmico - o que não quer dizer que se ignorem as diferenças entre um e outro, como se 
verá. Viveiros de Castro (2002), apesar de não tratar especificamente da autoantropologia, é quem vislumbra o potencial político dessa proposição epistemológica.

\section{DE PERTO}

Nascido na aldeia do Panambizinho, Município de Douradina, Mato Grosso do Sul, Izaque João foi um dos muitos Kaiowá que tomaram seus primeiros anos de educação formal na Missão Evangélica Unida nos anos 1980. Como narra a introdução de seu trabalho, o programa pedagógico cristão da educação missionária contrastava com o nhande reko, o modo de ser Kaiowá, e ele dirigiu a atenção ao seu avô paterno, o velho Simbu, um reconhecido rezador Kaiowá (JOÃO, 2011, p. 14-22).

Foi com seu avô que Izaque teve a oportunidade de vivenciar pela primeira vez o ritual de batismo do milho saboró (JOÃO, 2011, p. 19). Adolescente, conta, não teve interesse em entender as regras e os procedimentos do rito, mas as obedecia fielmente - essa experiência seria o que permitiria, anos mais tarde, elaborar as perguntas no trabalho de campo do mestrado junto aos rezadores Kaiowá das aldeias de Panambi, Panambizinho e Sucuri'y. A esses rezadores, que "ajudaram ao longo da pesquisa realizada para a conclusão desse estudo" (JOÃO, 2011, p. 4), Izaque João dedica a sua dissertação.

A eles e à memória de seu avô. Aqui há um primeiro elemento que eu gostaria de sublinhar: a referência da dissertação de Izaque, desde o primeiro momento, é a da memória. Seus agradecimentos começam dizendo:

Este estudo me faz compartilhar com a memória social de meus antepassados, os quais proporcionaram um amplo conhecimento sobre o assunto tratado neste estudo, permitindo-me compreender melhor a construção do modo de ser dos Kaiowá (teko), a partir da interpretação do canto e interação com as famílias tradicionais das aldeias Panambi, Panambizinho e Sucuri'y. Por outro lado, por ser parte da comunidade de Panambi, na condução deste trabalho procurei honrar tudo que diz respeito ao mborahei e nhembo'e (cânticos e ensinamentos), sobretudo a história kaiowá dentro do contexto sociocultural do qual faço parte. (JOÃO, 2011, p. 6)

Eu mesmo tive um par de motivos pessoais para me comprometer com os Kaiowá em uma pesquisa acadêmica, obviamente não os mesmos de Izaque. No 
seu discurso, preocupado que está em produzir uma historiografia de seu povo, fica marcada uma continuidade entre a memória dos antepassados, o objeto e os sujeitos de sua pesquisa e seu encargo como pesquisador. Não à toa que afirma haver sentido "uma satisfação inigualável e muita responsabilidade durante a realização das pesquisas aqui apresentadas" (JOÃO, 2011, p. 6).

Pesa, então, sobre o autopesquisador, uma responsabilidade. Quando está ele próprio comentando sobre seu trabalho, Izaque João faz questão de sublinhar sua condição de indígena pesquisando "em casa": "A metodologia utilizada para a realização deste trabalho", diz a introdução, "é a chamada observação direta, porém realizada por um pesquisador Kaiowá que faz parte da comunidade indígena de Panambi" (JOÃO, 2011, p. 16). Este trecho é especialmente significativo: "Para a realização deste trabalho, portanto, utilizei ativamente os 'olhos' e os 'ouvidos' para a observação direta, tendo como instrumentos de registro o gravador digital, o caderno de campo e a máquina fotográfica digital".

Izaque cita diretamente o texto de Roberto Cardoso de Oliveira, em que se descreve o método da observação participante - o "ouvir", e o "olhar" - como duas muletas que permitem ao pesquisador "caminhar, tropegamente, na estrada do conhecimento" (CARDOSO DE OLIVEIRA, 1996 , p. 21). Valendo-se da imagem, a exposição metodológica segue:

Para mim, a metáfora utilizada acima se tornou um grande aliado no registro de informações relacionadas ao batismo do milho saboró, uma "muleta" não necessariamente para uso constante. Como faço parte da comunidade kaiowá de Panambi e sou falante na língua guarani, às vezes, para me apoiar com mais facilidade na prática da pesquisa acadêmica, utilizo certas "muletas" como instrumentos que me auxiliam na caminhada da pesquisa. Este é o caso do uso do gravador para registrar as histórias e a sequência dos cantos kaiowá. Contudo, verifiquei que muitas informações sobre o sistema tradicional kaiowá, especialmente quando se trata de aspectos do canto e da reza, não são transmitidas pelo diálogo formal ou informal, como ocorre durante uma entrevista. Elas são transmitidas, isto sim, através de sua plena execução, as quais podem ser observadas e registradas por um pesquisador indígena que se posiciona e interage com paciência, humildade, respeito e atenção diante de seus pares interlocutores. (JOÃO, 2011, p. 16)

Infere-se daí que a condição de indígena, de falante da língua guarani e de participante ativo do ritual, mais do que como mero observador, são prerrogativas 
do pesquisador nativo das quais careceria o acadêmico não indígena. Isso considerado, o recurso do gravador e da câmera digital perde importância, e o elemento "participação" na observação direta permitiria um acesso direto a informações que, de outra sorte, não estariam disponíveis.

Poder-se-ia concordar ou discordar, é verdade. Veremos adiante que essa condição aparentemente natural de pesquisador nativo vai e vem, é marcada e desmarcada, no correr da dissertação. Se são essas as principais referências diretas de Izaque João à sua condição de cientista de seu próprio povo, o que se depreende em síntese é de que residem nela pelo menos duas implicações. A primeira seria de ordem metodológica, considerando que o autoantropólogo teria condições de participar dos modos tradicionais de transmissão e acessar níveis de conhecimento de outra maneira indisponíveis. A segunda, de ordem epistemológica, por assim dizer: se o pesquisador está debruçado por sobre seu povo, em alguma medida está debruçado por sobre si mesmo. A autoantropologia necessariamente tem de considerar a subjetividade do pesquisador - sua experiência, suas memórias, sua narrativa - como o marco-zero da derivação do conhecimento.

Voltando à questão inicial, há aí um projeto político? Se há, não está declarado em forma de manifesto, petição de princípios. Mas por que haveria de estar? O que há é uma expectativa: "espero que o presente estudo", diz o último parágrafo da introdução, "realizado de dentro da sociedade kaiowá para fora, possa servir, inicialmente, de registro de alguns de nossos cantos kaiowá, os quais certamente servirão para refletirmos sobre o nosso modo de ser (nhande rokoha kaiowa)". "Espero ainda", o texto segue, "que sirva para a valorização e o respeito da sociedade Kaiowá perante a sociedade nacional dos karai kuera ou não-índios" (JOÃO, 2011, p. 22).

Uma mensagem aos Kaiowá, outra à sociedade envolvente. A autoantropologia, aí, corta ambos os lados.

\section{DE LONGE}

Referi-me até quase que só à parte inicial e final da dissertação. Adentremos os capítulos a ver como, e se, essas pretensões se desenvolvem. 
Além da introdução e das considerações finais, o trabalho está dividido em três capítulos. O primeiro segmento, intitulado "Aspectos da Vida Religiosa no Tekoha Guasu", traz uma leitura xamânica da história Kaiowá, desde o tempo do "grande território" (ka'guyrusu) até o processo de aldeamento forçado nas reservas criadas pelo Serviço de Proteção ao Índio a partir dos anos 1930. Xamânica, digo, porque a narrativa histórica põe especial atenção no papel do rezador (nhanderu) na sociabilidade Kaiwoá, que envolve relações entre seres humanos, não humanos, almas e espíritos. O Jerosy Puku, canto ritual de batismo do milho saboró, é apresentado como instrumento de relação com a divindade protetora dos cultivares (Jakaira), que define tanto o manejo do clima como a reprodução do tempo entre os Kaiowá. O segundo capítulo descreve a sequência de três blocos do Jerosy Puku com a transcrição de longos trechos, acompanhados da análise das teorias cosmológicas Kaiowá fundamentadas no próprio canto. O terceiro capítulo está dedicado a outro tipo de canto ritual, chamado Kotyhu, cuja finalidade é expor publicamente os sentimentos do cantor - uma singular lírica indígena. Os Kotyhu também vêm transcritos - alguns deles, traduzidos - e contextualizados na sociabilidade Kaiowá.

O que impressiona já à entrada da exposição é a mudança de tom. Ao contrário da introdução, a linguagem é impessoal e objetiva, o desenvolvimento é analítico. Há argumentos e contra-argumentos, premissas e derivações. Há um distanciamento do interlocutor em relação aos sujeitos de sua pesquisa, reafirmado a todo tempo por meio da invocação do discurso dos rezadores como discurso especializado: Izaque recorre a expressões como "os xamãs contam que..." (JOÃO, 2011, p. 27), "os líderes espirituais Kaiowá acreditam que..." (JOÃO, 2011, p. 26).

A fórmula poderia ser defendida afirmando que a pretensão era justamente construir uma narrativa xamânica da história Kaiowá; e que a linguagem xamânica, com efeito, não é imediatamente acessível a qualquer interlocutor, ainda que indígena. E eu poderia concordar, se o autor não recorresse a expressões ainda mais generalizantes para introduzir suas explanações, como "no sistema kaiowá tradicional..." (JOÃO, p. 26), ou "na concepção kaiowá..." (JOÃO, 2011, p. 29).

Ao contrário do que se fazia na introdução, não há preocupação em localizar a pesquisa ou identificar os interlocutores. Izaque João só individualiza 
os nhanderu e nhandesy que informam sua pesquisa nas fotos que ilustram a dissertação, quase todas exibindo leiras de rama de mandioca ou milho saboró. Nas legendas, o nome do xamã dono do roçado; mas apenas duas imagens - já no capítulo dois, que trata dos cantos especificamente - retratam os "informantes", dão-Ihe cara e corpo e permitem ao leitor imaginar as condições da coleta de dados para a pesquisa.

Seria esse o efeito do que Izaque João sublinhava do detrimento do uso do gravador e da câmera como "muletas" de pesquisa, em favor da participação direta como pesquisador nativo? Seria esse um efeito de se produzir uma etnografia "de dentro pra fora" da sociedade Kaiowá: a impessoalização das informações colhidas? Em todo capítulo 1, em que repousa a parte analítica mais geral da dissertação, não há citação direta de nenhum rezador, apesar das constantes referências às explicações deles da cosmovisão Kaiowá. Nos capítulos 2 e 3 , as citações diretas da fala dos xamãs são a transcrição bruta dos cantos; no que concerne aos comentários quanto à sua estrutura e regras de performance, novamente encontramos a impessoalidade e a generalização.

A única referência a um locutor específico está na página 36. Mencionando brevemente o convívio com uma rezadora, Izaque João deixa transparecer a negociação a que estava sujeita a coleta de informações em campo:

No ano de 2009, minha interlocução com dona Anália Zevito foi bastante produtiva para me aproximar e conquistar a confiança de sua família extensa. Em várias ocasiões, durante as conversas em sua residência, na aldeia Panambi, a rezadora me forneceu informações importantes sobre as regras de cultivo do milho saboró. De acordo com sua narração, é necessário cultivar e zelar bem pelo desenvolvimento do milho saboró, de acordo com as regras. Assim, através de seu consumo, Jakaira incorpora a alma da pessoa que o consumiu, dando ênfase à voz e possibilitando ao corpo ser protegido dos espíritos antissociais. Pereira (2004, p. 26), em estudo citado anteriormente, relata que "plantar e consumir milho significa para o grupo o desejo (ou direito e dever) de exercer importantes prerrogativas políticas e religiosas". (JOÃO, 2011, p. 36-7)

Note-se que tampouco há uma citação direta da fala da rezadora; há, isso sim, uma transcrição de um trecho do doutorado de Levi Marques Pereira. Referências assim são constantes: Izaque faz citações diretas e assertivas de uma vasta gama de autores da etnologia, eles mesmos - não indígenas - analistas 


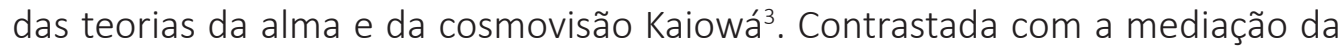
fala dos xamãs, a citação direta da fortuna etnológica intriga: para construir um discurso analítico de uma historiografia Kaiowá e do papel que os cantos Jerosy Puku e Kotyhu desempenham na sociabilidade envolvida nessa história, o autor se marca fora desse universo e produz, sobre ele, uma totalidade.

Podemos levantar algumas hipóteses diante dessa alteridade articulada no singular e conjugada no presente etnográfico. Poderia ser, talvez, uma estratégia discursiva para dotar de legitimidade acadêmica o trabalho científico de um pesquisador indígena. Talvez seja uma mimese, uma emulação nativa do discurso científico. Talvez, sendo Kaiowá, o autor simplesmente tenha se sentido confortável o suficiente para tecer considerações mais generalizantes e não oferecer uma caracterização maior dos seus informantes. Talvez, sendo Kaiowá, o autor tenha assumido a posição de resguardar os rezadores entrevistados por ele - qual, exatamente, a necessidade de identificá-los, expondo-os talvez ao risco ou à perturbação de uma reprodução descontrolada de seus nomes, das suas imagens e das suas vozes?

Ou ainda: não seria esse registro tão só e simplesmente o produto de um trabalho científico sério, respaldado por uma etnografia meticulosa? Qual é exatamente a diferença da dissertação de Izaque João dos trabalhos de qualquer um dos etnólogos que ele cita? No corpo dos capítulos, não há menção alguma ao fato de o pesquisador ser indígena e membro da comunidade pesquisada. $A$ informação só passa marcada na introdução e na conclusão do trabalho.

Seja qual for a solução dessas incertezas, creio que elas teriam de ser discutidas com o próprio Izaque, e eu não tive a chance. Em todo caso, não me parece que se desviem da questão inicial que dirigiu esta análise, qual seja, a de entender se a autoantropologia teria por natureza uma vocação política, um compromisso com os projetos do seu próprio povo.

Alguém poderia dizer que o trabalho de Izaque João não está dedicado exatamente ao conflito pela retomada das terras no qual estão envolvidos atualmente os Kaiowá. Ao começo do primeiro capítulo, adverte-se:

\footnotetext{
${ }^{3}$ Entre os autores clássicos da literatura Kaiowá e Guarani, João cita em sua dissertação Nimuendaju (1987), Cadogan (1992), Schaden (1963) e Melià, Grünberg \& Grünberg (1976); da literatura mais recente, além de Pereira (2004), estão Mura (2006), Chamorro (1995; 2008), Tempass (2005) e Vietta (2007), todos trabalhos reconhecidos na "guaraniologia".
} 
O estudo das aldeias Panambi, Panambizinho e Sucuri'y, pertencentes aos Kaiowá, não se reporta à situação social recente destas comunidades, mas à discussão relativa ao tekoha, a partir das categorias de construção da identidade e afirmação política, no domínio do território. Entendo que é necessário explicitar a lógica de uso do território na percepção kaiowá, para, dessa forma, aprofundar alguns aspectos a respeito da ocupação do tekoha guasu, no período da existência do Ka'aguyrusu. (JOÃO, 2011, p. 23)

Não é, de fato, um manifesto. Tal como na introdução, o autor não revela abertamente um engajamento do trabalho em um projeto político imediato, mas uma expectativa de verem aprofundadas e explanadas concepções próprias da territorialidade e da história Kaiowá.

Se considerarmos que, na atual conjuntura de Mato Grosso do Sul, simplesmente afirmar a validade de qualquer concepção própria indígena já soa desconfortável aos ouvidos de alguns; se considerarmos que não há nenhuma terra indígena Kaiowá que não enfrente no momento problemas na atenção básica à saúde, na segurança alimentar e no acesso ao território; se considerarmos que é nesse contexto que Izaque João vai à universidade, ingressa em um programa de pós-graduação em História sem políticas afirmativas e sustenta um mestrado que trata de aprofundar o entendimento de categorias próprias do seu povo - e para o seu povo, como ele mesmo ressalta -, a defesa de seu trabalho tem, por si só, conotações políticas.

Essa aparente variação no discurso - que às vezes põe o autor como voz interna e às vezes como mero analista da comunidade estudada - pode ser entendida como reflexo do processo de tradução no qual está engajada essa dissertação. Antropólogos nativos e não nativos já refletiram sobre essa capacidade reflexiva da antropologia. Vejamos o que Fahim e Helmer (1980), Narayan (1993) e Strathern (1987) podem elucidar do trabalho de Izaque João.

\section{AUTOANTROPOLOGIAS}

Não enderecei maiores comentários ao fato de que a dissertação de Izaque tenha sido defendida em programa de pós-graduação em História, e não Antropologia Social, porque essa é uma questão menor. O método utilizado para a pesquisa foi o etnográfico; os temas subjacentes a ela são temas antropológicos 
- cosmovisões, xamanismo, territorialidade; e, ainda que se pudesse dizer que há uma preocupação diacrônica, o tempo não é objeto de uso exclusivo da história. Tampouco o estudo dos povos indígenas é objeto exclusivo da antropologia. $\mathrm{Na}$ bibliografia citada, entre tantos antropólogos, constam só dois historiadores Antonio Brand e Jorge Eremites de Oliveira, este último o orientador da dissertação, citado em coautoria com o antropólogo Levi Marques Pereira.

Talvez a defesa deste trabalho no programa de pós-graduação em História, e não no de Antropologia, revele algo sobre a crítica Kaiowá ao trabalho antropológico que mencionei a início, mas essa é só mais uma incerteza. São incertezas quase todas as considerações que teci até agora, e não acho que seja por acaso. É o primeiro mestrado em História defendido por um Kaiowá4 e a presença indígena nos programas de pós-graduação ainda é algo novo e experimental nas universidades brasileiras. Neste sentido, a análise dos meandros do discurso acadêmico de Izaque João devem considerar esse pioneirismo: hoje ainda carecemos de espaço nas universidades para programas de pesquisa que garantam a inclusão e a produção de estudos antropológicos por indígenas; em 2011, então, o esforço dos professores da Universidade Federal da Grande Dourados para inclusão dos Kaiowá no mestrado e doutorado em História e Antropologia apenas dava seus primeiros frutos.

Entre eles, está a dissertação de Izaque, produzida com os recursos limitados que provavelmente condicionaram seu acesso a trabalhos acadêmicos desenvolvidos por indígenas, quanto menos por outros Kaiowá. Sua dissertação carrega este tom exploratório, o de um pesquisador que testa suas possibilidades entre a intuição e a interlocução com a fortuna antropológica. Seria preciso considerar, portanto, sua experiência acadêmica: as condições de produção do conhecimento antropológico são também objeto da antropologia.

Permitam-me, no entanto, tratar do que penso ser o cerne da coisa apenas a partir das informações de que disponho, isto é, do texto final e defendido da dissertação. Se hoje a questão já está mais lapidada inclusive pelas

\footnotetext{
${ }^{4}$ Tonico Benites foi o primeiro indígena Kaiowá-Guarani a receber o título de mestre, dois anos antes de Izaque João, ao defender a dissertação "A Escola na Ótica dos Ava Kaiowá: impactos e interpretações indígenas", no Programa de Pós-Graduação em Antropologia Social da Universidade Federal de Mato Grosso do Sul.
} 
contribuições do próprio Izaque, quando o termo "antropologia indígena" ou "antropologia at home" surgiu na Academia nos anos 1980, o que se celebrava era o fato de que o acesso dos antropólogos nativos à universidade permitiria à disciplina romper barreiras linguísticas e culturais e acessar com maior profundidade dados e informações coletadas em campo. Nesse sentido, Fahim e Helmer comentam que

As vantagens do insider incluem uma visão mais compreensiva da macrossociedade à qual a comunidade local é conectada e a habilidade de coletar dados íntimos e inestimáveis entendimentos dos sistemas de símbolos e valores cujos detalhes talvez confundam perpetuamente o estrangeiro. Os antropólogos indígenas têm a vantagem de conhecer os processos humanos de que carecem os modelos abstratos. (FAHIM; HELMER, 1980, p. 646, tradução livre do autor).

Seria exatamente essa a vantagem de um pesquisador nativo, em relação a um não nativo? Barreiras linguísticas, a intimidade nas relações pessoais, não são passíveis de serem superadas também por um pesquisador não nativo, a depender de fatores como familiaridade com o tema pesquisado, tempo em campo etc.? O quão "em casa" estaria um indígena fazendo pesquisa em sua própria comunidade, pelo simples fato de ser indígena? O quão em casa estava Izaque João fazendo pesquisa entre os nhanderu e nhandesy do Panambi, Panambizinho, Sucuri'y?

Ao mesmo passo em que faz questão de se marcar membro da comunidade, o autor se afasta para caracterizar o discurso especializado dos rezadores, dizendo na introdução que sua história individual levou-o a caminhos contrastantes com o nhande reko, o modo de ser tradicional Kaiowá. Conforme seu próprio testemunho, e tal como muitos outros Kaiowá, Izaque João recebeu uma educação cristã. Se isso marcou um afastamento em relação à sua "identidade" indígena, é também a razão pela qual ele diz haver despertado interesse em aprofundar seus conhecimentos sobre as concepções próprias Kaiowá e as normas que regem as práticas tradicionais. A ambivalência no discurso é também uma ambivalência biográfica.

Narayan, cujo pai é indiano e a mãe americana, e ela antropóloga pesquisando na Índia, vem defender que essa intimidade com o campo é muito mais fluida e relacional do que propriamente substantiva e qualificadora do sujeito: 
Em vez de o paradigma enfatizar uma dicotomia entre outsider/insider ou observador/observado, proponho que, neste momento histórico, possamos encontrar mais lucrativamente cada antropólogo em termos de identificações mutáveis em meio a um campo de comunidades interpenetrantes e relações de poder. Os loci pelos quais nos alinhamos ou nos separamos daqueles a quem estudamos são múltiplos e estão em fluxo. (NARAYAN, 1993, p. 671, tradução livre do autor)

Na proposição da autora, todo pesquisador - seja ele indígena ou não - disporia de uma "identidade multiplex". A formulação de identidade cultural de Stuart Hall valeria para a identidade individual do antropólogo: ela tem um background, mas está em constante transformação. Ser considerado nativo ou não dependerá da maneira com que o pesquisador se posiciona e é posicionado em campo em relação ao histórico dessas variações (NARAYAN, 1993, p. 676).

Strathern (1987) critica esse degradé imensurável do distanciamento do pesquisador por esvaziar o conceito de "casa". Em sua formulação, a pergunta não é o quanto "em casa" estaria um pesquisador nativo, mas como um pesquisador nativo saberia que está em casa:

Considero, então, que há uma maneira de resgatar o conceito de "casa" de medições impossíveis de graus de familiaridade. O continuum obscurece uma quebra conceitual. O que também se deve saber é se o investigador/investigado está igualmente em casa, por assim dizer, com os tipos de suposição sobre a vida social que informam a inquirição antropológica. (STRATHERN, 1987, p. 16, tradução livre do autor)

A proposta de Strathern leva a vantagem de situar a antropologia, enquanto campo do conhecimento, como um projeto ocidental. Pelo menos desde que Malinowski regressou de Trobriand, os métodos da ciência antropológica estão pensados como ferramentas de descrição e circunscrição da alteridade, o que tem direcionamentos políticos menos inocentes do que alguns de nós gostaríamos de admitir. Revelando a maneira com que os conceitos analíticos do outro (primitivo, selvagem) são contextualizados e arquitetados, a antropologia não simplesmente serve aos interesses da dominação colonial, mas é ela mesma expressão basilar do espírito da colonização.

Por sobre as considerações de Strathern e o conceitual de Narayan, o que marcamos como uma mudança no registro discursivo da dissertação de Izaque 
João surge não como uma contradição do autor em relação à sua identidade étnica - o que é uma identidade étnica, afinal? -, mas como uma variação na posição do autor em relação ao seu próprio discurso.

$\mathrm{Na}$ introdução e na conclusão de seu texto, Izaque João faz questão de marcar sua posição próxima da comunidade, faz questão de assinalar que as condições de realização de sua pesquisa levam em conta um contínuo de identificação entre o pesquisador e os sujeitos pesquisados. Um contínuo de experiência, de memória, e de linguagem. Quando passamos ao corpo da dissertação, a relação do autor com o discurso analítico muda de posição e passamos a uma linguagem expositiva. Os sujeitos são despessoalizados e observados a partir de um ponto de vista externo, como no cânone antropológico.

Mas não exatamente como no cânone antropológico. Ou por familiaridade ou por emulação como ventilamos, ou por qualquer outro motivo, Izaque achou por bem não "dar nome aos bois", não fazer citações diretas dos nhanderu e nhandesy, mas diluir suas falas umas nas outras e na literatura etnológica e produzir uma totalidade Kaiowá. Isso, no entanto, não quer dizer que ele tenha dado uma preponderância ao academicismo científico não indígena, como se ele fosse melhor ou mais capaz de explicar as categorias próprias Kaiowá. Pelo contrário, é o discurso que emerge da síntese entre a experiência pessoal do pesquisador e a interlocução com os xamãs, ratificada pela literatura antropológica, que conduz a narrativa sobre os cantos Jerosy Puku e Kotyhu e seu lugar na sociabilidade nativa.

O autor até pode obscurecer sua condição de membro da comunidade pesquisada, mas não são teorias externas a ela que ele busca para dirigir sua exposição. Se há uma teoria social na dissertação de Izaque João, ela está produzida a partir de um esforço pela busca das premissas e derivações nativas. Nesse sentido, a autoantropologia que essa dissertação circunscreve está na linha das proposições de Strathern, quando afirma que não está em um contínuo de identificação entre o pesquisador e o pesquisado, mas em uma continuidade cultural:

A autoantropologia, ou seja, a antropologia realizada no contexto social que a produziu, na verdade tem uma distribuição limitada. As credenciais pessoais do antropólogo não nos dizem se ele está em casa nesse sentido. Mas o que ele/ela escreve, afinal, faz: se existe continuidade cultural entre os produtos de seus trabalhos e o que as pessoas da sociedade estudada produzem por conta própria. (STRATHERN, 1987, p. 17, tradução livre do autor) 
Nesses termos, faz-se mais clara a potência política da antropologia de Izaque João. Desde a introdução até a conclusão, independentemente do tempo, do número e da pessoa dos verbos que ele usa, seu relato se constrói como um relato de si mesmo.

\section{CONCLUSÃO}

O trabalho de João não carece, como apontei ao início, de um engajamento político expresso. A vocação militante da autoantropologia parece ser de outra ordem. Em "O Nativo Relativo", Eduardo Viveiros de Castro vislumbra a potência do imperativo epistemológico que envolve a "pressuposição fundamental de que os procedimentos que caracterizam a investigação são conceitualmente da mesma ordem que os procedimentos investigados" (VIVEIROS DE CASTRO, 2002).

A escrita de Izaque João manifesta uma consciência da diferença entre o discurso nativo e o discurso analítico-antropológico, tanto que varia entre um registro e outro. Longe de estar neutralizada a equivalência entre os sentidos do antropólogo e do nativo, Izaque a marca, a internaliza, a introduz, e a potencializa. É uma nova experiência que parece seguir a provocação de Viveiros de Castro: no lugar de o indígena acadêmico "admitir que somos todos nativos", ele leva "às últimas consequências a aposta oposta - que somos todos antropólogos, e não uns mais antropólogos do que outros" (VIVEIROS DE CASTRO, 2002).

Talvez de uma maneira meio débil ainda, talvez como uma provocação. Mas o trabalho de Izaque João deixa transparecer a potencialidade da autoantropologia de destronar o cânone científico para pôr a ciência no mesmo pé que a reza, marcadas nesse movimento as diferenças de discurso - já não é política o suficiente?

\section{REFERÊNCIAS}

ALMEIDA, Mauro William Barbosa de. "Ética e Antropologia", conferência ministrada a convite do Programa de Pós-Graduação em Antropologia Social da Universidade de São Paulo, 2013.

CADOGAN, Leon. Ayvy rapyta: texto místico de los Mbyá-Guarani del Guaiá. Asunción: Fundación Leon Cadogan/CEADUC/CEPAG, 1992. 
CARDOSO DE OLIVEIRA, Roberto. Práticas interétnicas e moralidade: porum Indigenismo (auto)crítico. In: CARDOSO DE OLIVEIRA Roberto; CARDOSO DE OLIVEIRA, Luís Roberto. Ensaios antropológicos sobre moral e ética. Rio de Janeiro: Tempo Universitario, 1996.

CHAMORRO, Graciela. Yvy raguyje: fundamento da palavra guarani. Dourados, MS: Editora UFGD, 2008.

CHAMORRO, Graciela. Kurusu ñe'ëngatu: palabras que la historia no podría olvidar. Asunción: Universidad Católica Nuestra Señora de La Asunción, 1995.

DECLARAÇÃO DE BARBADOS. 1971. Disponível em: https://www.missiologia.org.br/ wp-content/uploads/cms_documentos_pdf_28.pdf, Acesso em: 3 abr. 2020.

FAHIM, Hussein; HELMER, Katherine. Indigenous anthropology. In: Non-western countries: a further elaboration [and comments]. Current Anthropology, v. 21, n. 5, p. 644-63, 1980.

JOÃO, Izaque. Jakaira Reko Nheypyrũ Marangatu Mborahéi: origem e fundamentos do canto ritual Jerosy Puku entre os Kaiowá de Panambi, Panambizinho e Suciri'y, Mato Grosso do Sul. 2011. Dissertação (Mestrado em História) - Universidade Federal da Grande Dourados (UFGD), Dourados, MS, 2011.

LEITE, Ilka Boaventura (Org). Laudos periciais antropológicos em debate. Rio de Janeiro: Associação Brasileira de Antropologia, 2005.

MELIÀ, Bartomeu; GRÜNBERG, Georg; GRÜNBERG, Friedl P. Etnografía guaraní del Paraguay contemporáneo: los Pai-Tavyterã. Suplemento Antropológico, Asunción, v. 11, n. 1-2, p. 151-295, 1976.

MURA, Fabio. A procura do "bom viver": território, tradição de conhecimento e ecologia doméstica entre os Kaiowá. 2006. Tese (Doutorado em Antropologia) - Museu Nacional, Universidade Federal do Rio de Janeiro, Rio de Janeiro, 2006.

NARAYAN, Kirin. How native is a native? America Anthropologist, v. 95, n. 3, p. 671-86, 1993.

NIMUENDAJU, Curt. As kebdas da criação e destruição do mundo como fundamento da religião dos Apapocúva Guarani. São Paulo: HUCITEC/USP, 1987.

PEREIRA, Levi Marques. Imagem Kaiowá do sistema social e seu entorno. 2004. Tese (Doutorado em Antropologia Social) - Universidade de São Paulo, São Paulo, 2004. 
SCHADEN, Egon. Aspectos fundamentais da cultura guarani. São Paulo: EPU/EDUSP, 1963.

STRATHERN, Marilyn. The limits of auto-anthropology. In: JACKSON, Anthony. (Org.). Anthropology at home. London: Tavistock, 1987.

TEMPASS, Martim César. Orerembiú: a relação das práticas alimentares e seus significados com a identidade étnica e a cosmologia Mbyá Guarani. 2008. Tese (Doutorado em Antropologia Social) - Universidade Federal do Rio Grande do Sul, Porto Alegre, 2008.

VIETTA, Katya. Territorialidade e organização social na perspectiva dos kaiowá de Panambizinho (Dourados-MS) após 170 anos de exploração e povoamentos não indígenas na fronteira entre o Brasil e Paraguai. 2007. Tese (Doutorado em Antropologia) - Universidade de São Paulo, São Paulo, 2007.

VIVEIROS DE CASTRO, Eduardo. O nativo relativo. Mana, Rio de Janeiro, v. 8, n. 1, p. 113-48, abr. 2002.

\section{Sobre o autor:}

Bruno Martins Morais: Doutorando em Direito Socioambiental e Sustentabilidade pela Pontifícia Universidade Católica do Paraná (PUCPR). Mestre em Antropologia Social e graduado em Direito pela Universidade de São Paulo (USP). Sua dissertação de mestrado, intitulada "Do corpo ao pó: crônicas da territorialidade Kaiowá nas adjacências da Morte", foi publicada pela Editora Elefante, com o apoio da ANPOCS. E-mail: bruno@moraiseazanha.adv.br, Orcid: https://orcid.org/0000-0001-8024-3245

Recebido em 9 de setembro de 2019.

Aprovado para publicação em 18 de novembro de 2019. 
